\title{
Enhancing Student Learning In Mechanics of Material Course Through Contextual Learning
}

\author{
Roopa A. K. ${ }^{1}$, Anand M. Hunashyal ${ }^{2}$ \\ ${ }^{1,2}$ School of Environmental and Civil Engineering, KLE Technological University, Hubballi \\ roopa.ak@bvb.edu \\ ªmhunashyal@bvb.edu
}

\begin{abstract}
Mechanics of materials is a foundational and interdisciplinary course for mechanical, civil, and aerospace engineering disciplines. It provides a fundamental understanding of the mechanical properties of various materials and their behavior subjected to different kinds of loading. In Civil engineering, basic concepts learned through this course are the prerequisite for various higher-level courses such as structural analysis and design of various structural elements. Teaching a course on Mechanics of Material is challenging as it involves mathematical formulation and calculations which needs a student to have critical thinking skills and different orientations to understand this subject. Therefore this paper describes contextual learning of the Mechanics of Material by associating the classroom teaching to real-world experiences. A practical assignment is given to students at the end of each course chapter, so that students can visually inspect the structural members and visualize its behavior subjected to various forces, stresses deformation developed in a real-time structure to enhance learning efficiency. The object of this work is to promote experiential learning, critical thinking and to upgrade knowledge regarding innovations in new structural materials through contextual learning. The
\end{abstract}

Roopa A. K.

School of Environmental and Civil Engineering, KLE Technological University, Hubballi roopa.ak@bvb.edu course delivery and assessment strategies were meticulously executed in the form of assignments to foster experiential learning that leads to the attainment of higher levels in graduate attributes as related to Bloom's taxonomy in the cognitive domain. This pedagogical transition effect was measured in the form student feedback surveys, and course learning outcomes. It was observed that the strategies helped students with better understanding of the subject.

Keywords: Contextual learning, Mechanics of Material, Practical/Theoretical Assignment, Realtime structures.

\section{Introduction}

Engineering education involves a methodological identification of skill sets or attributes that potential employers in society would demand from a student pursuing the programme. The purview of this emerging stream of knowledge and practice extend towards bringing reforms in design-delivery and assessment of course-ware to equip effective student learning. Henceforth pedagogical reformation is essential in engineering education to bring a higher level in teaching methodology compared to the conventional way of teaching [3]. This reformation puts students into the province of learning through experience and discovery by providing them with enough information. The main object of today's education is to bridge the gap between classroom learning to real-time problems. Hence contextual learning approach helps teachers connect content that 
students learn academically with real-world situations that usually students experience. Since mechanics of material is a basic core subject in the civil engineering stream, it has applications in a wide range of areas. The study of mechanics of material impacts the design of structural elements like RCC, PSC, steel .etc. Thorough knowledge of the subject makes the students understand the behaviour of structures under critical loading conditions and helps in designing of structural elements. Since mechanics of material involves mathematical formulation and calculations, it needs a student to have very critical thinking skills and different orientations to understand this subject. Hence it becomes necessary to emphasize contextual learning to make the students familiarize with concepts in structural mechanics and understand the physical significance.

\section{Literature Review}

Claire et al. [1] describe the introduction of a sustainable metrics (SusMet) Module to engineering students to understand the concepts of design for endof-life and design for disassembly (explicit) and sustainable metrics (implicit) through active and experiential learning in the disassembly of green office chairs, to establish the cognition and perceptions of sustainability. The SusMet Module was implemented in one intro-level course (Intro p Ret) where students participated in the entire module and one Intro - Act $p$ Ret course (Intro - Act $p$ Ret) where the activity portion of the module was removed. Both the Intro $p$ Ret and Intro - Act $p$ Ret courses completed a design retention assignment two weeks after the module to understand the impact of the activity on the retention of learning objectives. Retention of learning objectives was most impacted by the activity portion of the module; students that participated in the activity and completed an additional design assignment post module (Intro $\mathrm{p}$ Ret class) retained module-learning objectives to a greater degree than students that did not participate in the activity but also completed the design assignment [1].

Yao et al. [4] examine how the experimentoriented teaching in Strength of Materials in contrast to the math-oriented approach enhances learning efficiency. New experiments emphasized visually observable mechanical behavior so that students could visually inspect the deformation of members when subjected to different types of loadings. The students were first engaged in class through the introduction to equations and relevant examples on the textbooks. Then, the lab component with visible features enables them to examine the applicability of the equations which improved learning [4].

N. Bolong et al.[7] compares the implementation of traditional (expository) with open-ended laboratory (problem-based) for two consecutive cohorts studying environmental laboratory course in civil engineering program. For both cases of study, the implementation stages were categorized into conceptual, experimental work and report stage. The changes of approach at each stage were differentiated in the concept given to students, allotted time frame, instructor and demonstrator role, and the written report format and assessment feedback/monitoring techniques. It was observed that students have demonstrated better performance in their grades and $12 \%$ increase in the course outcome (CO) in problembased open-ended laboratory style than traditional method [7].

Sasithorn et al. [10] implemented E-learning to promote the students' learning on the topic Basic Computer Programming for undergraduate students. Three sources of personalized information, including personalized learning problems, personalized learning styles, and personalized learning achievement, were used to determine the personalized subject materials on the topic. The developed elearning environment can be used to work with an online learning system by giving personal guidance and appropriate learning material to each student based on their online learning performance. To evaluate the performance of this developed e-learning environment 23 undergraduate students were recruited to participate in this study. It is found that the developed E-learning environment could help students gain more conceptual knowledge on the topic and they had positive attitude toward learning in this e-learning environment [10].

\section{Methodology of course delivery}

In the present study, the Mechanics of Materials course was taught at the 3rd semester of the undergraduate program in Civil Engineering. The details of the course outcomes defined are listed in Table 1. The assessment plan for the course included a continuous internal assessment (CIE) and Semester End Assessment (SEE) based on the curriculum content. The CIE and SEE segments had uniform 
weightage to decide the student's performance for this 4-credit theory course over a 50-hour student contact. The details of the assessment and the mapping of course out outcomes with Program Outcomes are detailed in Table 1 and Table 2, respectively. The present study is based on a sample of 148 students. There were 62 female respondents and 86 male respondents.

The basic concepts learned through this course are the prerequisite for various higher level courses involving the structural analysis and design of various

\section{Table 1 : Course Outcomes (COs)}

1. Define and explain the various terms connected to the mechanics of materials.

2. Evaluate the different types of stresses /strains that are developed in a material due to external loading and evaluate mechanical properties

3. Compute and construct SF / BM diagrams that are developed at various points in a beam, for a given loading, and for given support conditions due to external loading.

4. Compute and construct Bending /Shearing stresses diagrams that are developed at various points across the cross-section in a beam due to external loading.

5. Determine the deflections in a beam for given loading, at various points for different types of beams and support conditions.

6. Evaluate the load-carrying capacity and critical stresses for long columns under axial loading by different methods.

7. Determine compound stresses under multiple loading systems for a given material section.

8. Determine the torsional stresses for round section material subjected to a torque.

9. Corelate classroom teaching to real-time structures and to develop lifelong learning

Table 2 : Mapping of Co to PO's

\begin{tabular}{|c|c|c|c|c|c|c|c|c|c|c|c|c|}
\hline $\begin{array}{l}\text { Course } \\
\text { Outcomes } \\
\text { (COs) / } \\
\text { Program } \\
\text { Outcomes } \\
\text { (POs) }\end{array}$ & 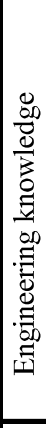 & $\begin{array}{l} \\
\\
\\
0 \\
0 \\
0 \\
0 \\
0 \\
0 \\
0 \\
0 \\
0 \\
0 \\
0 \\
0\end{array}$ & 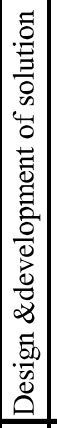 & 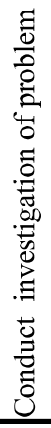 & 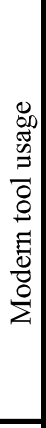 & 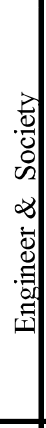 & 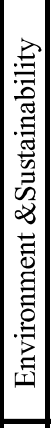 & 泀 & 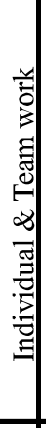 & 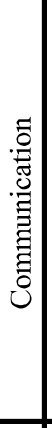 & 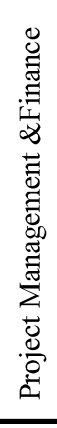 & 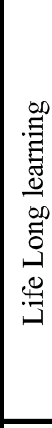 \\
\hline $\mathrm{CO} 1$ & $\mathbf{M}$ & & & & & & & & & & & \\
\hline $\mathrm{CO} 2$ & $\mathbf{M}$ & & & & & & & & & & & \\
\hline $\mathrm{CO} 3$ & $\mathbf{M}$ & $\mathbf{L}$ & & & & & & & & & & \\
\hline $\mathrm{CO} 4$ & $\mathbf{M}$ & & & & & & & & & & & \\
\hline
\end{tabular}

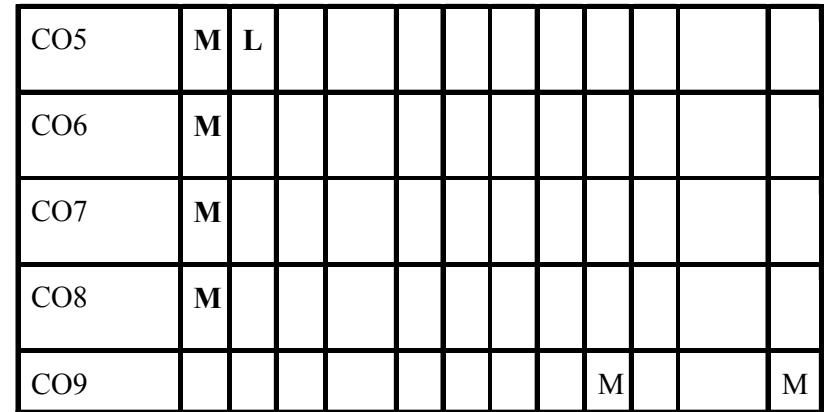

structural elements. The teaching of mechanics of materials is challenging as it involves a significant amount of mathematical formulation. Students find it difficult to relate mathematical formulation to the real-time behaviour of structures. Hence it becomes necessary to co- relate classroom teaching to field problems. In earlier assessment assignment included only theoretical questions which will increase the problem solving skills. In present assessment an attempt is made to enhance the learning outcomes by connecting to the practical problems. Course assignment includes theoretical and practical assignment, each carrying the five marks. Theoretical assignment involves learning of procedures, methodology and mathematical formulation to carry out the analysis. In practical assignment students corelate the real time field problem to the classroom learning to understand the physical significance. This contextual learning was implemented as a group activity. Groups of 5-6 students were formed and were asked collect the data from field to determine the forces, stress, load carrying capacity etc. in various existing structural elements. This exercise targets a few chapters in the mechanics of materials to make the student familiarize themselves with the relationship between forces and moment, deformation by actually seeing the real world structural elements. The sample of the assignment questions is described in Table 3. Practical questionaries are solved by corelating classroom teaching to real-time structures and to develop lifelong learning (CO9), as students need to collect the required field data on their own. The field exposure ensures the understanding of practices and technology involved and promotes critical thinking which is an essential component of lifelong learning skills (PO12). Similarly the questionnaires were formed for all chapters. The assessment of assignments is carried out as described in Table 4. In the theoretical assignment students solve the numerical portion after analysing the given data followed by proper methodology, whereas in practical assignment students collected data from field such as 
dimensions, types of building etc., then they have to analyse the problem by correlating class learning.
Each team was evaluated for the conceptual knowledge, technical information and written communication skills through the submitted report.

Table 3: Assignment Questionnaires

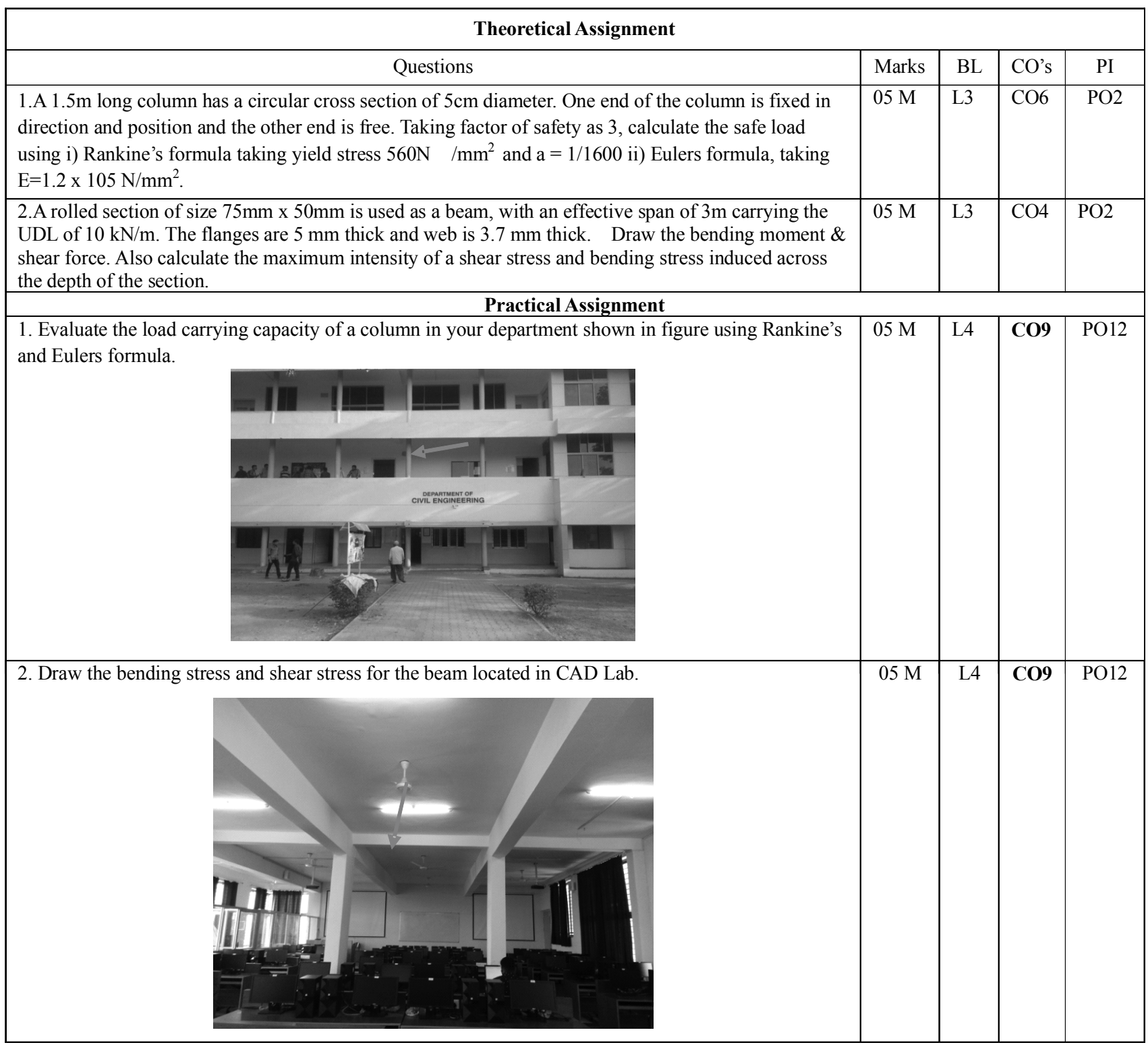

Table 4: Assessment Scheme

\begin{tabular}{|c|c|c|c|c|c|}
\hline Parameters & Marks & PO & HIGH (100\%) & MEDIUM (60\%) & LOW (20\%) \\
\hline \multicolumn{6}{|c|}{ Theoretical assignment } \\
\hline $\begin{array}{l}\text { Data Analysing } \\
\text { and } \\
\text { Methodology }\end{array}$ & 03 & $\begin{array}{l}\text { PO 01: } \\
\text { Engineering } \\
\text { Knowledge }\end{array}$ & $\begin{array}{l}\text { Able to Analyse the } \\
\text { given data and identifying } \\
\text { the proper methodology } \\
\text { to solve the problems. }\end{array}$ & $\begin{array}{l}\text { Able to Analyse the given } \\
\text { data and not understanding } \\
\text { the methodology to solve } \\
\text { the problems. }\end{array}$ & $\begin{array}{l}\text { Unable to Analyse } \\
\text { the given data itself. }\end{array}$ \\
\hline $\begin{array}{c}\text { Solving } \\
\text { Numerical }\end{array}$ & 02 & $\begin{array}{l}\text { PO 02: } \\
\text { Problem } \\
\text { Analysis }\end{array}$ & $\begin{array}{l}\text { Able to apply } \\
\text { mathematical } \\
\text { formulations to get } \\
\text { correct answers. }\end{array}$ & $\begin{array}{l}\text { Able to apply mathematical } \\
\text { formulations but unable to } \\
\text { get correct answers. }\end{array}$ & $\begin{array}{l}\text { Unable to solve the } \\
\text { problems. }\end{array}$ \\
\hline
\end{tabular}




\begin{tabular}{|c|c|l|l|l|l|}
\hline \multicolumn{5}{|c|}{} & \multicolumn{5}{|c|}{ Practical Assignment } \\
\hline Data collection & 01 & $\begin{array}{l}\text { PO 02: } \\
\text { Problem } \\
\text { Analysis }\end{array}$ & $\begin{array}{l}\text { Able to collect the data } \\
\text { from the field and } \\
\text { interpret and }\end{array}$ & $\begin{array}{l}\text { Able to collect the data from } \\
\text { the field not capable to } \\
\text { interpret }\end{array}$ & $\begin{array}{l}\text { Able to collect the } \\
\text { data from the field, }\end{array}$ \\
\hline Data Analysing & 02 & $\begin{array}{l}\text { PO 12: } \\
\text { Lifelong } \\
\text { learning } \\
\text { Skills }\end{array}$ & $\begin{array}{l}\text { Able to apply } \\
\text { conceptual knowledge } \\
\text { to solve the problem }\end{array}$ & $\begin{array}{l}\text { Able to apply conceptual } \\
\text { knowledge but unable to } \\
\text { solve the problem }\end{array}$ & $\begin{array}{l}\text { unable to apply } \\
\text { conceptual } \\
\text { knowledge to solve } \\
\text { the problem }\end{array}$ \\
\hline Presentation & 02 & $\begin{array}{l}\text { PO 09: } \\
\text { Teamwork }\end{array}$ & $\begin{array}{l}\text { Able to present the } \\
\text { work in the report. } \\
\text { Able to explain the } \\
\text { work, their contribution } \\
\text { to team. }\end{array}$ & $\begin{array}{l}\text { Able to present the work in } \\
\text { the report. } \\
\text { Not Able to explain the } \\
\text { work, their contribution to } \\
\text { team, }\end{array}$ & $\begin{array}{l}\text { Not presenting the } \\
\text { work in the report } \\
\text { Not Able to explain } \\
\text { the work, their } \\
\text { contribution to team }\end{array}$ \\
\hline
\end{tabular}

\section{Result and Discussion}

This study opened the scope of analyzing the real world structures with the theoretical knowledge learned in the classroom. In practical assignment students will get exposed to new and innovative construction materials and technology that are used as they need to visit the field to collect the data. This exercise makes students think critically for example, from Table 3 in order to find out the load carrying capacity of column and stress induced in beam of real structures, students must able to think different loads acting (Self weight and Live load) on the structures, their pattern end conditions (Fixed and simply supported) on structures.

Contextual learning promotes active and highly collaborative learning(PO 09) and helped students to identify gaps in knowledge by and collecting necessary technical information which will help them in lifelong learning skills (PO12). This mode of learning stimulates clear understanding of the concept, which brings better clarity in concept among students as well as higher level of realization in the bloom's taxonomical level as students need to collect and analyze the data to solve real-time structures by applying the classroom knowledge. Henceforth it is observed that practical assignment questionnaires helped to elevate the bloom level's taxonomy from L3 to L4 shown in Fig.1 which will lead to a higher level of learning attainment. Assignment evaluation was more effective compared to earlier method, where marks were allocated based only on numerical problem solving skills. This exercise definitely created an interest in learning process as observed by the instructor. However, the data showed only a marginal increase in performance of attainment of practical assignment shown in Fig.3 compared to attainment of theoretical assignment in Fig.2. Here attainment is described as the percentage of students that have been assessed to have performed beyond a

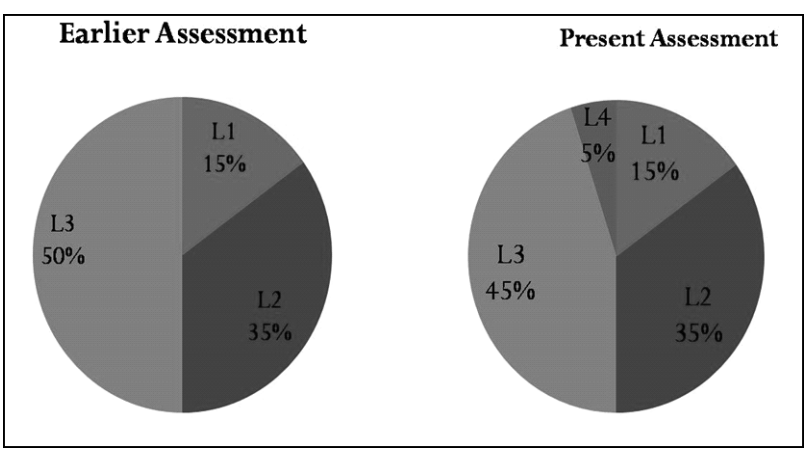

Fig.1: Impact on Distribution of Bloom level Taxonomy

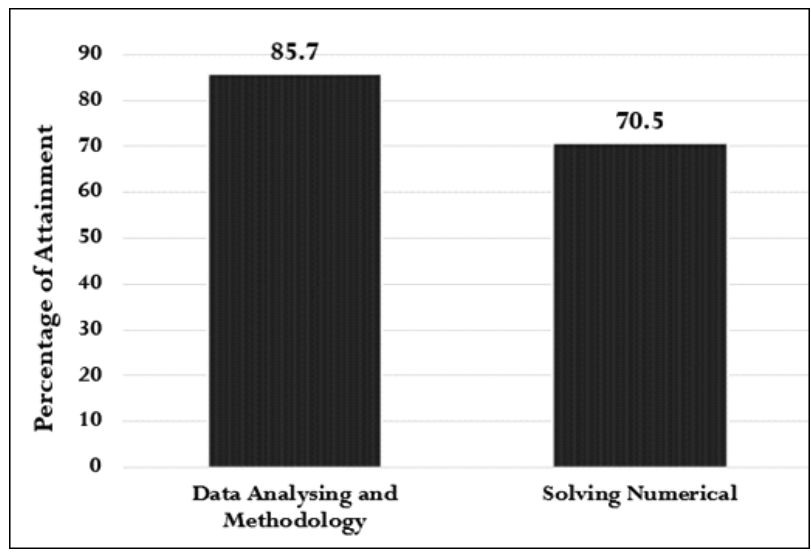

Fig. 2: Attainment of Theoretical Assignment

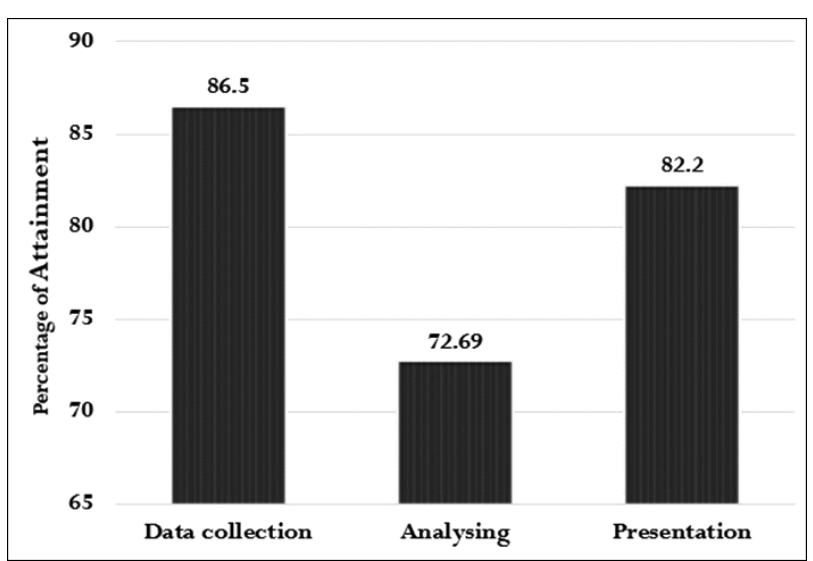

Fig. 3: Attainment of Practical Assignment 


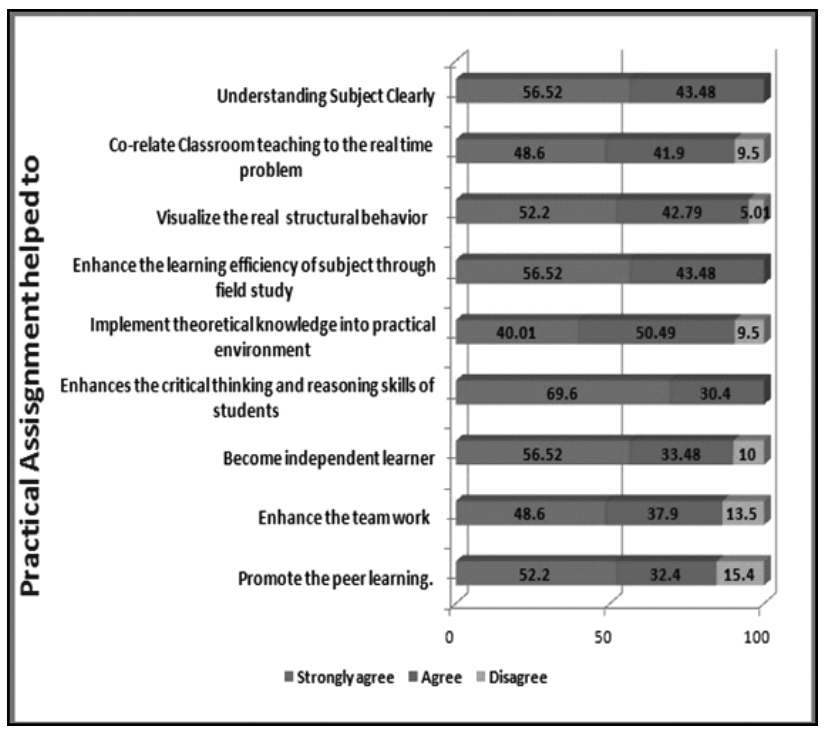

Fig. 4: Students Feedback

certain percentage of marks. The impact of this exercise on the students' perception of learning was measured by collecting feedback as described in Fig.4. In Fig. 4, Q1 and Q4 had the highest approval from the students indicating that most students perceived that their learning was improved through the current intervention. Even though teamwork and peer learning related questions also had high agreement from the students they had a sizable number of disagreements as expected possibly because some students did not like to work in teams. Overall, it was found that they had positive attitude toward the contextual learning environment with clear understanding of concept, problem analyzing skills, lifelong learnings and teamwork.

\section{Conclusions}

This paper describes contextual learning of mechanics of material course. This exercise helps the students correlate theoretical learning to real world experience, making the students to think critically and analyze the real-world problems which will enhance the learning skills. Contextual learning helps build active and highly collaborative learning, a clear understanding of concept, problem analyzing skills lifelong learning skills..

\section{Acknowledgment}

The authors would like to thank Dr. Ashok Shettar Vice Chancellor of KLE Technological University, Dr. P. G. Tewari, Principal, and Dr. S.S. Quadri, Head of Department, School of Environmental and Civil
Engineering for their continuous guidance and motivation for this innovative practice and during the execution of this activity.

\section{References}

[1] Claire L. A. Dancz, A.M., Melissa M, and Amy E. Landis, "Active Experiential Sustainable Engineering Module for Engineering Education", American Society of Civil Engineers, Feb 2018, ISSN 1052-3928.

[2] Reshmi Devi T.V, "Implementing Project-based Learning in Civil Engineering- A Case Study", Journal of Engineering Education Transformations, Volume 30, No. 3, January 2017, ISSN 2349-2473, eISSN 2394-1707

[3] N.R. Banapurmath, P.P. Revankar, R.S. Hosmath, M.B. Gorwar, "Pedagogical Reforms in Delivery of Undergraduate Heat and Mass Transfer Course towards Enhancements in Student Learning", Journal of Engineering Education Transformation, Volume 30, No. 3, January 2017, ISSN 2349-2473, eISSN 2394-1707

[4] Yao George C., Kuo Keng-Chang, Hsueh ChengLuen and Tang Yao, "A New Approach to Teach Mechanics of Material Through Touching Experience ", American Journal of Civil Engineering, 2016,Vol. 4, No. 4, pp. 143-148.

[5] David E.Goldberg, Mark Somerville, "The Making of A Whole New Engineer: Four Unexpected Lessons for Engineering Educators and Education Researchers", Journal of Engineering Education, January 2015, Vol. 104, No. 1, pp. 2-6.

[6] Steven Randall Chesnut, Hansel Burley, Selfefficacy as a predictor of commitment to the teaching profession: A meta-analysis, Educational Research Review, Volume 15, June 2015, Pages 116

[7] KatrienVangrieken, FilipDochy, ElisabethRaes, Eva Kyndt, Teacher collaboration: Asystematic review, Educational Research Review, Volume 15, June 2015, Pages 17-40

[8] M. TariqBanday ,MusavirAhmed ,Tariq R. Jan, Applications of e-Learning in engineering 
education: A case study, Procedia - Social and Behavioral Sciences 123 (2014) 406 - 413

[9] Murat Sonmez, The Role of Technology Faculties in Engineering Education, Procedia - Social and Behavioral Sciences 141 (2014) 35 - 44

[10]Sasithorn Chookaew, Patcharin Panjaburee , Dechawut Wanichsan, Parames Laosinchai, "A Personalized E-Learning Environment to Promote
Students' Conceptual Learning on Basic Computer Programming", Procedia - Social and Behavioral Sciences, Elsevier Ltd.,2013, 116 ( 2014) 815-819

[11]FatinAliahPhang,KhairiyahMohdYusof,Taking the "Guess-work" Out of Engineering Education:Establishing the Virtuous Cycle of Research, Procedia - Social and Behavioral Sciences 102(2013) 212 - 220 